\title{
Studying the mechanism of PLAGL2 overexpression and its carcinogenic characteristics based on 3 -untranslated region in colorectal cancer
}

\author{
CHEN SU* , DAOJIANG LI*, NANPENG LI, YUHENG DU, CHUNXING YANG, \\ YANG BAI, CHANGWEI LIN, XIAORONG LI and YI ZHANG
}

Department of Gastrointestinal Surgery, The Third Xiangya Hospital of Central South University, Changsha, Hunan 410013, P.R. China

Received November 11, 2017; Accepted March 2, 2018

DOI: 10.3892/ijo.2018.4305

\begin{abstract}
Pleomorphic adenoma gene like-2 (PLAGL2) is a zinc finger protein transcription factor, which is upregulated and serves an oncogenic function in multiple human malignancies, including colorectal cancer (CRC). First, reverse transcriptionquantitative polymerase chain reaction (RT-qPCR) was used to detect the expression levels of PLAGL2 in CRC tissues and normal tissues. Then, bioinformatics analysis, RT-qPCR, western blotting, luciferase reporter assays and RNA-binding protein immunoprecipitation assays were performed to explore whether the underlying mechanisms, including copy number variation (CNV), microRNAs (miRNAs/miRs) and RNA-binding proteins (RBPs) led to the abnormal expression of PLAGL2. Finally, cell counting kit-8 assays, Transwell assays and xenograft models were used to detect carcinogenesis-associated characteristics based on the 3'-untranslated region (3'-UTR) of PLAGL2. In the present study, PLAGL2 was revealed to be upregulated in CRC tissues compared with normal CRC tissues. CNV was one of the causes leading to the upregulation of PLAGL2. miRNA, including downregulated miR-486-5p, and RBPs, including upregulated human antigen $\mathrm{R}(\mathrm{HuR})$, were other key underlying causes. In addition, PLAGL2 3'-UTR was revealed to promote the progression of CRC in vitro and in vivo, and to regulate the expression of C-MYC and CD44. To conclude, these results suggested that
\end{abstract}

Correspondence to: Dr Yi Zhang, Department of Gastrointestinal Surgery, The Third Xiangya Hospital of Central South University, 138 Tongzipo Road, Changsha, Hunan 410013, P.R. China

E-mail: yzhangxy3@csu.edu.cn

${ }^{*}$ Contributed equally

Abbreviations: CRC, colorectal cancer; $\mathrm{CNV}$, copy number variation; RPBs, RNA-binding proteins; 3'-UTR, 3'-untranslated region.

Key words: pleomorphic adenoma gene like-2, 3'-untranslated region, copy number variation, microRNA-486-5p, human antigen R, colorectal cancer high expression of PLAGL2 in CRC was associated with CNV, miR-486-5p and HuR expression, whose 3'-UTR may promote colon carcinogenesis and serve as a novel potential biomarker for CRC therapies.

\section{Introduction}

The pleomorphic adenoma gene like (PLAGL) gene family includes PLAGL1, PLAG1 and PLAGL2. As a zinc finger protein transcription factor, PLAGL2 possesses seven $\mathrm{C} 2 \mathrm{H} 2$ zinc finger domains on the N-terminal (1-3). PLAGL2 shows similar DNA-binding affinity to the homologous PLAG1, which serves a carcinogenic function in tumor development (4). PLAGL2 was initially discovered in mouse cell lines and fetal tissues $(2,3)$ and exerts various biological effects. PLAGL2 has been demonstrated to induce cell cycle blockage and apoptosis in human promonocytic U937 cells (5) and to regulate Wnt signaling to impede differentiation in neural stem cells (6). At present, an increasing number of studies PLAGL2, as with PLAG1, focus on pathological tumorigenesis. For instance, overexpression of PLAGL2 contributes to the development of human acute myeloid leukemia (7), and is associated with prognosis and survival in female patients with lung adenocarcinoma (8). Zheng et al (6) suggested that PLAGL2 functions as a oncogene and exerts stem cell-like characteristics in glioma-initiating cells (6). Furthermore, accumulating evidence has shown that overexpression of PLAGL2 serves a carcinogenic role in gastrointestinal cancer $(9,10)$. Liu et al (9) reported that the expression of PLAGL2 was associated with tumor size in gastric cancer. Wang et al (10) demonstrated that PLAGL2 induced epithelial-mesenchymal transition via the $\mathrm{Wnt} / \beta$-catenin signaling pathway in colorectal cancer (CRC) (10).

PLAGL2 is located at 20q11. A previous study by our group demonstrated that PLAGL2 is one of the top 20 frequently mutated and highly expressed genes at 20q11 in CRC, and The Cancer Genome Atlas (TCGA) database analysis indicated that the expression rate of PLAGL2 is up to $48.36 \%$ (11). Although several studies have focused on the expression of PLAGL2 and its carcinogenic mechanisms, the mechanisms that result its high expression in CRC are unclear. An increasing number of 
studies have reported that gene expression was driven by copy number variation $(\mathrm{CNV})$ in various cancer $(12,13)$. Therefore, in the present study, our group explored the mechanism of high expression of PLAGL2 in CRC at the CNV level. Furthermore, because PLAGL2 possesses a long 3'-UTR (3,948 bp), which contains a relatively large number of predicted microRNAs (miRNAs/miRs) and retinol binding protein (RBP) binding sites, the present study investigated potential miRNAs and RBPs to demonstrate the other mechanisms underlying overexpression of PLAGL2 in CRC.

Pilot experiments revealed that the PLAGL2 3'-UTR expression level is also increased in CRC compared with normal tissues. The 3'-UTR may be transcribed independently and may not be dependent on the coding regions involved in the development of cellular processes (14). For instance, cluster of differentiation (CD)44 3'-UTR activates collagen type $1 \alpha 1(\mathrm{Col} 1 \alpha 1)$ and fibronectin 1 (FN1) by competitive binding to miRNAs, and thus enhances cell motility and invasion in a human breast carcinoma cell line, MDA-MB-231 (15). As a competing endogenous RNA (ceRNA), versican-3'-UTR promotes the expression of CD34 and participates in the development of hepatocellular carcinoma (16). To investigate whether PLAGL2 3'-UTR participates in CRC processes, PLAGL2 3'-UTR was overexpressed and its involvement in the progression of CRC cells was observed in in vitro and in vivo experiments. At the same time, potential ceRNA genes that are indirectly regulated by PLAGL2 3'-UTR were screened for. These studies will provide a theoretical basis for a deeper understanding of the mechanism underlying PLAGL2 regulation in CRC progression.

\section{Materials and methods}

Specimens. CRC specimens and adjacent tissues were obtained from the Third Affiliated Hospital of Central South University between January, 2017 and May, 2017 (Changsha, China). All samples were immediately flash-frozen in liquid nitrogen after resection and then stored at $-80^{\circ} \mathrm{C}$. All samples had a clear histologic diagnosis of CRC from experienced pathologists, and patients did not undergo chemotherapy or radiotherapy prior to the operation. Signed consent forms were provided by all patients. The present study was approved by The Institute Research Medical Ethics Committee of Central South University.

Xenograft model. BALB/C nude mice $(\mathrm{n}=30$, female, 5-weeks-old, $\sim 18 \mathrm{~g}$ ) were purchased from SJA Laboratory Animal Company (Changsha, China). All mice were kept under specific pathogen-free conditions with a 12-h light/dark cycle and autoclaved food/water were provided freely. In order to ensure that the mice did not develop too enlarged tumors (e.g., a tumor size of $>2 \mathrm{~cm}$ ), the mice were closely monitored. SW620 and HCT116 cell suspensions (5x10 6 in $100 \mu$ l PBS) that were stably transfected with LV-PLAGL2 3'-UTR Front/Back or LV-Vector (Shanghai GenePharma Co., Ltd., Shanghai, China) following the manufacturer's instructions were injected into the backs of nude mice ( $\mathrm{n}=5$ for each group). For further details of lentivirus transfection, please see the section below entitled 'Plasmid and lentivirus constructs'. Tumor volume was measured every three days from 10 days after inoculation, and the following formula: Tumor volume $\left(\mathrm{mm}^{3}\right)=\left(\right.$ length $\mathrm{x}$ width $\left.{ }^{2}\right) / 2$ was used to calculate the tumor volume. All mice were sacrificed after 30 days, and the removed tumors were weighed. Nude mice and animal protocols used in the present study were approved by the Animal Ethics Committee of Central South University.

Cell culture. The human CRC cell lines SW620 and HCT116 were purchased from Wuhan Boster Biological Technology, Ltd. (Wuhan, China). SW620 cells were cultured in L15 medium (Nanjing KeyGen Biotech Co., Ltd., Nanjing, China) supplemented with $10 \%$ fetal bovine serum (FBS; Biological Industries Israel Beit-Haemek, Beit-Haemek, Israel). HCT116 cells were incubated in McCoy's5A medium (Nanjing KeyGen Biotech Co., Ltd.) supplemented with 10\% FBS (Biological Industries Israel Beit-Haemek). All cells were incubated at $37^{\circ} \mathrm{C}$ with $5 \% \mathrm{CO}_{2}$.

Reverse transcription-quantitative polymerase chain reaction (RT-qPCR). Total RNA was extracted using TRIzol reagent (Invitrogen; Thermo Fisher Scientific, Inc. Waltham, MA, USA). RT-qPCR was performed with the Toyobo RT kit and KOD SYBR ${ }^{\circledR}$ qPCR kit (Toyobo Life Science, Osaka, Japan) following the manufacturer's protocol. mRNA primers were synthesized by Sangon Biotech Co., Ltd. (Shanghai, China), and miRNA-specific RT primers and PCR primers were synthesized by Guangzhou RiboBio Co., Ltd. (Guangzhou, China). The PCR thermocycling conditions were as follows: $2 \mathrm{~min}$ at $98^{\circ} \mathrm{C}$; 40 cycles of $10 \mathrm{sec}$ at $98^{\circ} \mathrm{C}, 10 \mathrm{sec}$ at $60^{\circ} \mathrm{C}$, and $30 \mathrm{sec}$ at $68^{\circ} \mathrm{C}$; and $5 \mathrm{~min}$ at $72^{\circ} \mathrm{C}$. Standard curve analysis was used to assess amplification efficiency. The primer sequences are listed in Table I. All mRNA expression was normalized to GAPDH, and miR-486-5p expression was normalized to U6. The expression levels of mRNAs and miRNAs were determined by the $2^{-\Delta \Delta \mathrm{Cq}}$ method. All experiments were performed in triplicate.

Western blotting. Proteins were extracted with RIPA lysis (Nanjing KeyGen Biotech Co., Ltd., Nanjing, China) for $30 \mathrm{~min}$ at $4^{\circ} \mathrm{C}$ and measured by BCA protein assay. Protein samples $(40 \mu \mathrm{g})$ were separated by $10 \%$ SDS-PAGE (Suzhou Well-Bridge Biological Technology Co., Ltd, Suzhou, China) and transferred to PVDF membranes (Invitrogen; Thermo Fisher Scientific, Inc.). Following blocking with 5\% non-fat milk in PBST for $2 \mathrm{~h}$ at $37^{\circ} \mathrm{C}$, membranes were incubated overnight with primary antibodies at $4^{\circ} \mathrm{C}$. Following washing membranes with PBST, the membranes were incubated with HRP-conjugated goat anti-rabbit IgG $(1: 10,000)$ (cat. no. SA00001-2) and HRP-conjugated goat anti-mouse IgG (1:10,000) (cat. no. SA00001-1) (both from SanYing Company, Wuhan, China) for $120 \mathrm{~min}$ at room temperature. The bound antibody was detected by HRP substrate. All samples were performed in triplicate. The details of the primary antibodies used were as follows: Anti-human antigen R (HuR; cat. no. ab136542), anti-PLAGL2 (cat. no. ab139509) (Abcam, Cambridge, UK), anti-C-MYC (cat. no. 10828-1-AP) and anti-CD44 (cat. no. 15675-1-AP) (both from ProteinTech Group, Inc., Chicago, IL, USA) at a 1:1,000 dilution; and anti-GAPDH (cat. no. ab181602; Abcam) at a 1:3,000 dilution.

Cell counting kit-8 (CCK-8) assay. Cell proliferation was tested using CCK-8 (Dojindo Molecular Technologies, Inc., Kumamoto, Japan), once cells were stably transfected with 
Table I. Primer sequences list $\left(5^{\prime} \rightarrow 3^{\prime}\right)$.

\begin{tabular}{|c|c|}
\hline Gene & Primer sequence \\
\hline \multirow[t]{2}{*}{ Vimentin } & F: GACGCCATCAACACCGAGTT \\
\hline & R: CTTTGTCGTTGGTTAGCTGGT \\
\hline \multirow[t]{2}{*}{ SRC } & F: GAGCGGCTCCAGATTGTCAA \\
\hline & R: CTGGGGATGTAGCCTGTCTGT \\
\hline \multirow[t]{2}{*}{ RHOC } & F: GGAGGTCTACGTCCCTACTGT \\
\hline & R: CGCAGTCGATCATAGTCTTCC \\
\hline \multirow[t]{2}{*}{ RPS6KA3 } & F: CGCTGAGAATGGACAGCAAAT \\
\hline & R: TCCAAATGATCCCTGCCCTAAT \\
\hline \multirow[t]{2}{*}{ PRL-3 } & F: GCTTCCTCATCACCCACAАCC \\
\hline & R: ATCCTTCTCCAGCGGCGTTT \\
\hline \multirow[t]{2}{*}{ MYC } & F: GTCAAGAGGCGAACACACAAC \\
\hline & R: TTGGACGGACAGGATGTATGC \\
\hline \multirow[t]{2}{*}{ MLL2 } & F: GAGCTACGGCGCTTTGAGTT \\
\hline & R: AGGGAAACCAATCTGTGATAGG \\
\hline \multirow[t]{2}{*}{ MAVS } & F: CAGGCCGAGCCTATCATCTG \\
\hline & R: GGGCTTTGAGCTAGTTGGCA \\
\hline \multirow[t]{2}{*}{ LARP1 } & F: ACACAAGTGGGTTCCATTACAA \\
\hline & R: CTCCGCGATTGGCAGGTAT \\
\hline \multirow[t]{2}{*}{ HMGA2 } & F: ACCCAGGGGAAGACCCAAA \\
\hline & R: CCTCTTGGCCGTTTTTCTCCA \\
\hline \multirow[t]{2}{*}{$\mathrm{EZH} 2$} & F: GTACACGGGGATAGAGAATGTG \\
\hline & R: GGTGGGCGGCTTTCTTTATCA \\
\hline \multirow[t]{2}{*}{ E2F3 } & F: AGAAAGCGGTCATCAGTACCT \\
\hline & R: TGGACTTCGTAGTGCAGCTCT \\
\hline \multirow[t]{2}{*}{ CD44 } & F: CTGCCGCTTTGCAGGTGTA \\
\hline & R: CATTGTGGGCAAGGTGCTATT \\
\hline \multirow[t]{2}{*}{ C22ORF29 } & F: GACTTCTGATCCGCAGAGGGG \\
\hline & R: TCCGAGGCAATCTGAGGCTAC \\
\hline \multirow[t]{2}{*}{ GAPDH } & F: ACCTGACCTGCCGTCTAGAA \\
\hline & R: TCCACCACCCTGTTGCTGTA \\
\hline \multirow[t]{2}{*}{ PLAGL2 } & F: GAGTCAAGTGAAGTGCCAATGT \\
\hline & R: TGAGGGCAGCTATATGGTCTC \\
\hline PLAGL2 & F: ACTGTGGGACCCTTGAGACG \\
\hline 3'UTR Front & R: TGGTAGGAGGCTGAGGCAAT \\
\hline PLAGL2 & F AGAATAGCTTTATCCTGCACTC \\
\hline 3'UTR Back & R: GTCCCTCATTGGTCTTTGTC \\
\hline \multirow[t]{2}{*}{ HuR } & F: AACTACGTGACCGCGAAGG \\
\hline & R: CGCCCAAACCGAGAGAACA \\
\hline
\end{tabular}

F, forward; R, reverse

PLAGL2 3'-UTR lentivirus. For further details on lentivirus transfection, please see below (section entitled 'Plasmid and lentivirus constructs'). The SW620 or HCT116 cells ( $5 \times 10^{3} /$ well) were incubated in 96-well plates with $100 \mu 1$ normal culture medium at $37^{\circ} \mathrm{C}$, and at the indicated time points $(8,24,48$, 72 and $96 \mathrm{~h}$ ), $10 \mu \mathrm{l}$ CCK-8 solution was added to each well and the plates were cultured for $1 \mathrm{~h}$ at $37^{\circ} \mathrm{C}$. The absorbance of each well was detected using an EnVision microplate reader (PerkinElmer, Inc., Waltham, MA, USA) at $450 \mathrm{~nm}$ (A450). All experiments were performed in triplicate.
Cell migration and invasion assays. Cell migration and invasion assays were performed using a Transwell chamber $(8 \mu \mathrm{m}$, 24-well insert; Corning Incorporated, Corning, NY, USA) with or without Matrigel (BD Biosciences, Franklin Lakes, NJ, USA) coating. Once cells were stably transfected with PLAGL2 3'-UTR lentivirus, cells $\left(1 \times 10^{5}\right)$ were added to the upper chamber with serum-free medium, and normal medium containing $10 \%$ FBS was added to lower chamber. Then, SW620 and HCT116 cells were incubated at $37^{\circ} \mathrm{C}$ for $72 \mathrm{~h}$ and $30 \mathrm{~h}$, respectively. Finally, cells in the upper chamber were removed, and the membranes were soaked with methanol for $30 \mathrm{~min}$, stained with crystal violet solution for $15 \mathrm{~min}$, and cells below the membranes were counted under a fluorescence inverted microscope (Olympus Corporation, Tokyo, Japan). Invasion assays used the same steps as aforementioned, but Matrigel was used. All experiments were performed in triplicate.

Luciferase reporter activity assay. pmirGLO Dual-Luciferase miRNA Target Expression Vectors (Promega Corporation, Madison, WI, USA) that contained the coding sequences of Firefly luciferase and Renilla luciferase (internal control) were used to examine whether PLAGL2 3'-UTR was a target of miR-486-5p in vitro. First, $8 \times 10^{5}$ cells/well were seeded in 24-well plates the day prior to transfection. Cells were then co-transfected with wild-type (wt) PLAG2 3'-UTR pmirGLO plasmid or mutant (mut) PLAG2 3'-UTR pmirGLO plasmids and miR-486-5p mimics or miR-NC using Lipofectamine 2000 (Invitrogen; Thermo Fisher Scientific, Inc.) according to the manufacturer's protocol. Luciferase activity was detected after $48 \mathrm{~h}$ with the dual-luciferase reporter assay system (Promega Corporation). All experiments were performed in triplicate.

Transfection of miRNAs and plasmids. miR-486-5p mimics (5'-UCCUGUACUGAGCUGCCCCGAG-3') and miR-NC (5'-UUUGUACUACACAAAAGUACUG-3') were purchased from Guangzhou RiboBio Co., Ltd., and plasmid constructs were purchased from OriGene Technologies, Inc. (Rockville, MD, USA). First, cells ( $5 \times 10^{5}$ cells/well) were seeded in 6 -well plates with normal mediun containing $10 \%$ FBS the day prior to transfection, then cells were transfected with miRNAs (final concentration: $50 \mathrm{nmol} / \mathrm{l}$ ) and plasmid constructs (final concentration: $2 \mu \mathrm{g} / \mathrm{ml}$ ) using Lipofectamine 2000 (Invitrogen; Thermo Fisher Scientific, Inc.) and Opti-MEM medium (Thermo Fisher Scientific, Inc.) following the manufacturer's protocol. Cells were used for further experiments $48 \mathrm{~h}$ after transfection.

RNA-binding protein immunoprecipitation (RIP). RIP was performed using a EZ-Magna RIP kit (Merck KGaA, Darmstadt, Germany) following the manufacturer's protocol. SW620 and HCT116 cell $\left(2 \times 10^{7}\right)$ pellets were washed with ice-cold PBS and resuspended with RIP lysis buffer. Then, Magnetic Beads Protein A/G was incubated with $5 \mu \mathrm{g}$ mouse monoclonal anti-HuR IgG (cat. no. ab136542; Abcam) or normal mouse IgG (negative control) (Merck KGaA) for $30 \mathrm{~min}$ at $37^{\circ} \mathrm{C}$, which were added to cells lysis buffer and immunoprecipitation buffer containing EDTA and RNase inhibitors. Complexes were incubated with rotation overnight at $4^{\circ} \mathrm{C}$. The following day, complexes were washed with wash buffer, digested with proteinase $\mathrm{K}$ and heated at $55^{\circ} \mathrm{C}$ for $30 \mathrm{~min}$. Finally, RNA was purified and subjected to qPCR. 
A
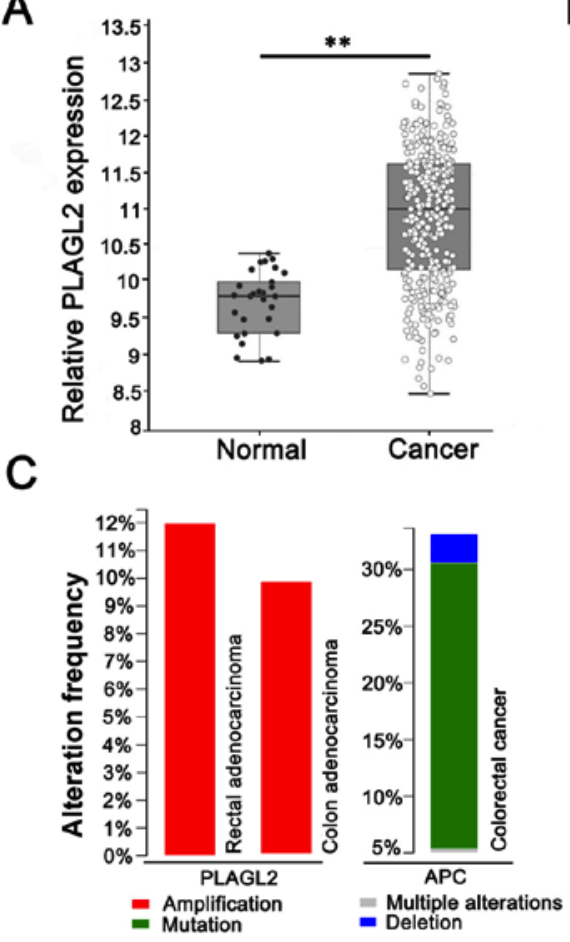

B
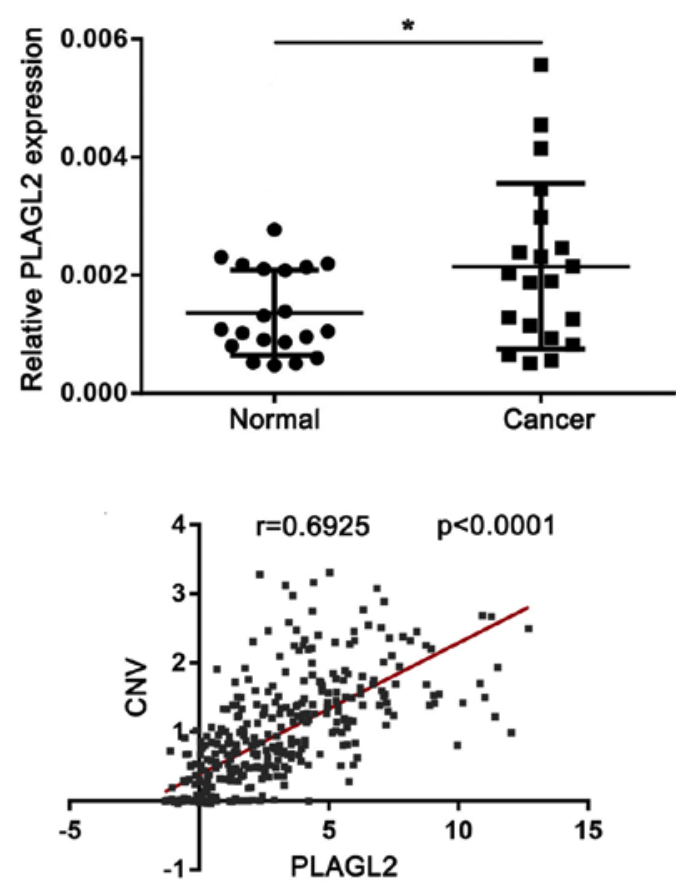

D

\begin{tabular}{|c|c|c|c|}
\hline \multirow{2}{*}{ Gene } & \multicolumn{3}{|c|}{ Copy number variation } \\
\hline \multirow{4}{*}{ PLAGL2 } & CNV gain & Total samples & $\%$ \\
\cline { 2 - 4 } & 56 & 771 & 7.26 \\
\cline { 2 - 4 } & \multicolumn{3}{|c|}{ Gene expression } \\
\cline { 2 - 4 } & Overexpressed & Total samples & $\%$ \\
\cline { 2 - 4 } & 295 & 610 & 48.36 \\
\hline
\end{tabular}

Figure 1. PLAGL2 expression and the association between CNV and PLAGL2 expression in CRC. (A) PLAGL2 expression in CRC samples and normal samples was analysed using starBase v2.0. (B) PLAGL2 expression in CRC tissues and normal tissues $(\mathrm{n}=20)$ was detected by reverse transcription-quantitative polymerase chain reaction. (C) The main somatic variation of the PLAGL2 gene and correlation analysis between CNV and PLAGL2 expression in CRC, through analyzing The Cancer Genome Atlas data. (D) CNV does not fully explain the high expression of PLAGL2 in CRC, as determined through analysing COSMIC data. Data are presented as the mean \pm standard deviation. ${ }^{*} \mathrm{p}<0.05$ and ${ }^{* *} \mathrm{p}<0.01$, with comparisons indicated by lines. PLAGL2, pleomorphic adenoma gene like-2; CNV, copy number variation; CRC, colorectal cancer.

Plasmid and lentivirus constructs. The wt 3'-UTR (422 bp) and mut 3'-UTR (422 bp) of PLAGL2 in the putative miR-486-5p binding sites were inserted downstream of the Firefly luciferase gene in the pmirGLO vector (Promega Corporation), and the complement sequence of HuR DNA were inserted into the pCMV6 vector (OriGene Technologies, Inc.). Lentiviral expression vectors, RNAi-Mate, and lentiviral packaging vectors, including pGag/Pol, pRev and pVSV-G, were purchased from Shanghai GenePharma Co., Ltd. (Shanghai, China), and a blank lentiviral expression vector was used as a control. Briefly, human 293T cells (Chinese Academy of Sciences Cell Bank, Shangshai, China) were cultured in $10 \mathrm{~cm}$ Petri dishes to $80-90 \%$ confluency and then inoculated into $15 \mathrm{~cm}$ Petri dishes (both from Corning Incorporated). The following day, human 293T cells were cotransfected with the lentiviral expression constructs, RNAi-Mate and lentiviral packaging vectors. The medium was collected $72 \mathrm{~h}$ after transfection and filtered with a $0.45 \mu \mathrm{m}$ filter (Sartorius AG, Gottingen, Germany). The abovementioned lentiviral packaging experiments were completed by GenePharma Co., Ltd. (Shanghai, China) following the manufacturer's instructions. Subsequently, $50 \mu \mathrm{l}$ viral supernatant and $5 \mu 1$ polybrene $(4 \mu \mathrm{g} / \mathrm{ml})$ were added to $5 \times 10^{5}$ cells seeded in each well of 6-well plates the previous day. Two days later, these transfected cells were cultivated in medium containing puromycin $(2 \mu \mathrm{g} / \mathrm{ml})$ (Beyotime Biotechnology, Shanghai, China). Finally, cells that were not successfully transfected were almost killed by puromycin on the fifth day, then we used these stably transfected cells for various assays. All constructs were confirmed by DNA sequencing.

Bioinformatics. The somatic mutations of PLAGL2 were analyzed using the TCGA database (http://www.cbioportal.org/) and COSMIC database (http://cancer.sanger.ac.uk/cosmic/). Potential miRNA targets of PLAGL2 were predicted using four publicly available programs: TargetScan (http://www.targetscan. org) (17), Starbase (http://starbase.sysu.edu.cn/index.php), Tarbase (http://carolina.imis.athena-innovation.gr) and miRTarBase (http://mirtarbase.mbc.nctu.edu.tw/php/index.php). Correlation analysis and expression of miRNAs and HuR were provided by StarBase v2.0 (http://starbase.sysu.edu.cn/index.php). 
A
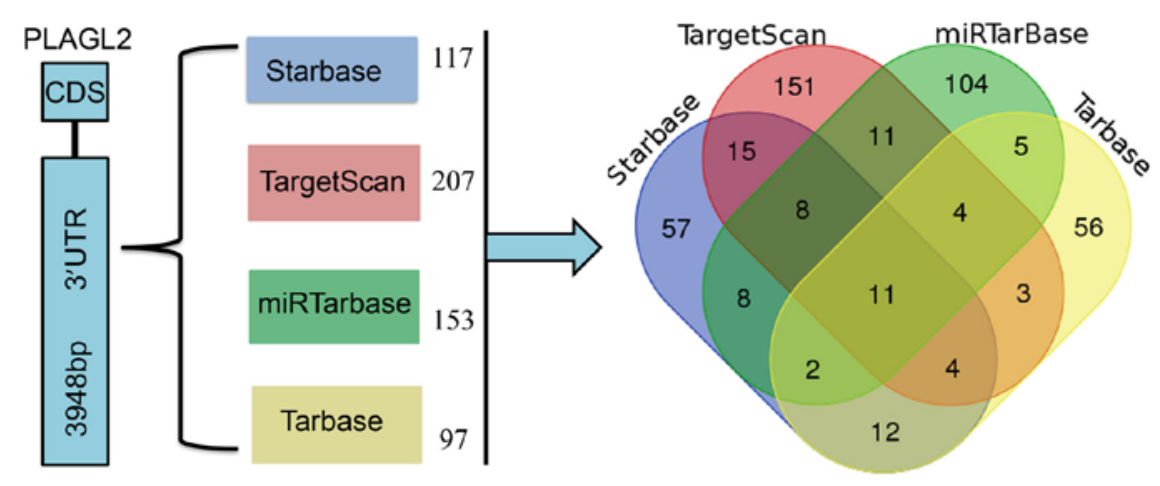

B
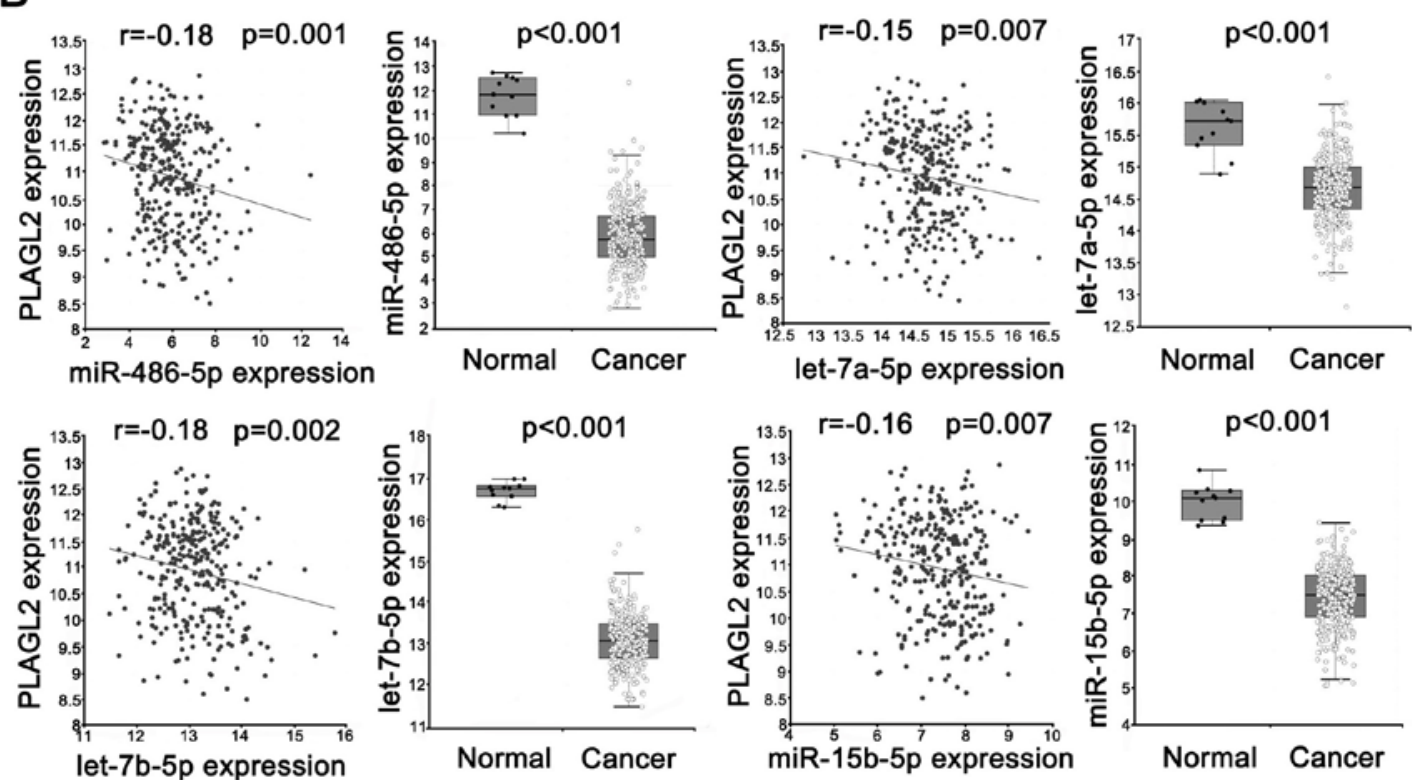

Figure 2. Bioinformatics analysis of the potential miRNAs of PLAGL2. (A) A venn diagram shows the potential miRNAs of PLAGL2, which were predicted by Starbase, TargetScan, miRTarBase and Tarbase software. (B) Correlation analysis and the expression of miRNAs in CRC were provided by Starbase v2.0. miRNA, microRNA; PLAGL2, pleomorphic adenoma gene like-2.

Statistical analysis. Statistical analysis was performed using SPSS 19.0 software (IBM Corp., Armonk, NY, USA). Data were imaged with GraphPad Prism 6 software (GraphPad Software, Inc., La Jolla, CA, USA) and expressed as the mean \pm standard deviation. Pearson's test was used in analyzing the correlation, Differences between groups were compared using Student's t-test (when 2 groups), and one-way ANOVA (when $>2$ groups) was used, followed by S-N-K method for comparing each two groups. $\mathrm{p}<0.05$ was considered to indicate a statistically significant difference.

\section{Results}

PLAGL2 is overexpressed in CRC tissues, and CNV may explain high expression of PLAGL2 in CRC. Consistent with previous studies $(9,10)$, PLAGL2 expression was revealed to be increased in CRC samples compared with normal samples through the starBase v2.0 analysis (Fig. 1A). Futhermore, RT-qPCR further validated overexpression of PLAGL2 in 20 paired CRC tissues compared with normal tissues (Fig. 1B). To investigate the mechanism of PLAGL2 overexpression in CRC, TCGA database analysis was performed. CNV was a major somatic variation of PLAGL2 and was positively correlated with the expression of
PLAGL2 in CRC (Fig. 1C), which suggested that CNV was the one of the causes of PLAGL2 overexpression in CRC. However, the CNV rate of PLAGL2 is only 7.26\%, while the gene expression rate is up to $48.36 \%$ in a cohort of CRC samples obtained through COSMIC database analysis (http://cancer.sanger. ac.uk/cosmic/; Fig. 1D), which indicated that CNV does not fully explain the high expression of PLAGL2 in CRC. To investigate the other mechanisms controlling PLAGL2 overexpression in $\mathrm{CRC}$, further studies are required.

Bioinformatics analysis of miRNAs for PLAGL2. PLAGL2 possesses a long 3'-UTR (3,948 bp), and miRNAs have been demonstrated to regulate gene expression by binding mRNA 3'-UTRs $(18,19)$. To screen potential miRNAs that regulate PLAGL2 expression, 11 common predicted miRNAs were screened out using 4 online miRNA target prediction databases, including Starbase, TargetScan, miRTarBase and Tarbase. These miRNAs included let-7a-5p, let-7b-5p, let-7d-5p, let-7e-5p, let-7f-5p, let-7g-5p, let-7i-5p, miR-138-5p, miR-212-3p, miR-132-3p and miR-486-5p (Fig. 2A). Next, using starBase v2.0 analysis, 5 miRNAs that were downregulated and negatively correlated with PLAGL2 in CRC were screened out, including miR-486-5p, let-7a-5p, let-7b-5p, 
A

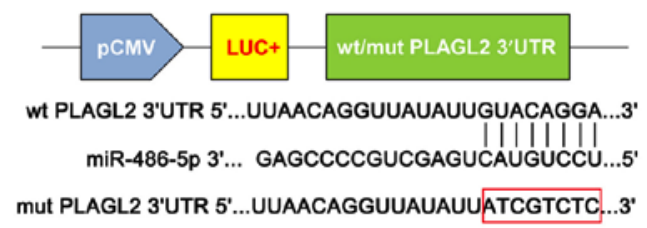

C

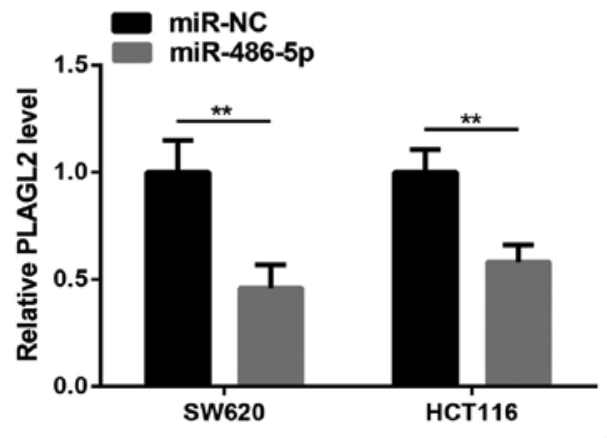

E

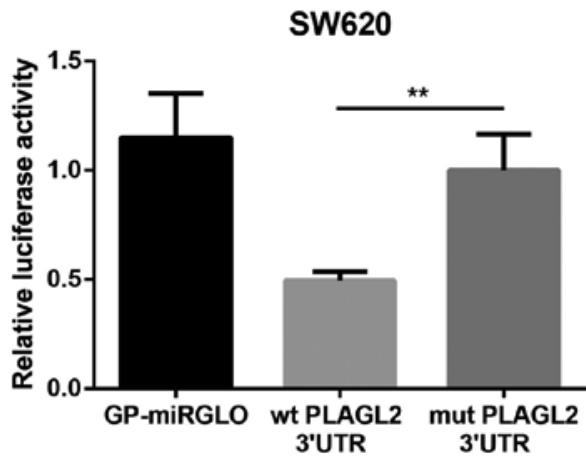

B

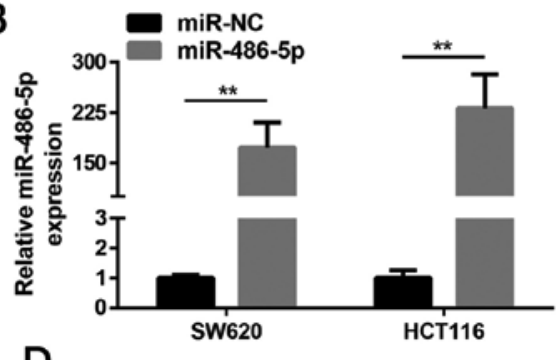

$\mathbf{F}$

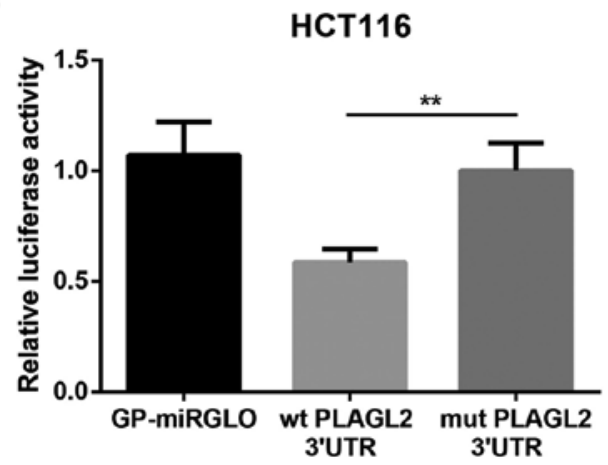

Figure 3. PLAGL2 is a target of miR-486-5p. (A) Diagram of the luciferase reporter plasmids, including the wt and mut PLAGL2 3'-UTR, are presented (B) miR-486-5p mRNA was detected by RT-qPCR in SW620 and HCT116 cells following transfection with miR-486-5p mimics and NC. (C) mRNA and (D) protein expression of PLAGL2 were detected by RT-qPCR and western blotting, respectively, in SW620 and HCT116 cells following transfection with miR-486-5p mimics and NC. GP-miRGLO was a negative control, where cells were co-transfected with miR-486-5p mimics and empty vector. The relative luciferase activity in (E) SW620 and (F) HCT116 cells transfected with miR-486-5p mimics was significantly decreased in the group co-transfected with wt PLAGL2 3'-UTR (pmirGLO-PLAGL2-wt) compaired with the group co-transfected with mut PLAGL2 3'-UTR (pmirGLO-PLAGL2-mut). Data are presented as the mean \pm standard deviation. ${ }^{* *} \mathrm{p}<0.01$, with comparisons indicated by lines. PLAGL2, pleomorphic adenoma gene like-2; miR, microRNA; 3'-UTR, 3'-untranslated region; RT-qPCR, reverse transcription-quantitative polymerase chain reaction; mut, mutant; wt, wild-type; NC, negative control.

miR-15b-5p and miR-132-3p (Fig. 2B). The data for miR132-3p was not shown, and more details are available from Starbase v2.0. From the above and through literature review, miR-486-5p was selected as the best candidate mRNA as it has been demonstrated to be involved in the progression of CRC (20). Further verification was then performed.

miR-486-5p directly targets PLAGL2 in CRC cells. To verify whether PLAGL2 is a target of miR-486-5p, a reporter plasmid assay containing wt and mut PLAGL2 3'-UTR by using pmirGLO Vector (Fig. 3). Then, the reporter vectors containing wt PLAGL2 3'-UTR and miR-486-5p mimics were co-transfected into SW620 and HCT116 cells. The activity of luciferase was significantly decreased compared with the control, which was co transfected with the reporter vectors containing mut PLAGL2 3'-UTR and miR-486-5p mimics (Fig. 3E and F). Furthermore, miR-486-5p mimics were successfully transfected into SW620 and HCT116 cells and transfection efficiency was detected by qPCR (Fig. 3B). The expression of PLAGL2 in the cells transfected with
miR-486-5p mimics was significantly decreased at the mRNA and protein levels compared with the control (Fig. 3C and D). These results indicated that PLAGL2 was negatively regulated by miR-486-5p in CRC cells.

HuR protein may stabilize PLAGL2 expression in CRC cells. In addition to miRNAs, multiple studies have reported that 3'-UTRs are regulated by RBPs. HuR is a well-known RBP that mainly binds to mRNA 3'-UTR and stabilizes the expression of mRNA $(21,22)$, and several studies have confirmed that high expression of HuR is associated with progression of CRC $(23,24)$. Notably, HuR was the top predicted RBP of PLAGL2 as predicted using starBase v2.0 analysis. Therefore, HuR was selected as a potential RBP that may stabilize PLAGL2 expression. Then, HuR expression was detected, and revealed to be elevated in CRC samples compared with normal samples, and positively correlated with PLAGL2 expression, using starBase v2.0 analysis (Fig. 4A and B). Western blotting further validated that HuR mRNA was overexpressed in CRC tissues compared with normal tissues (Fig. 4C). Furthermore, 
A

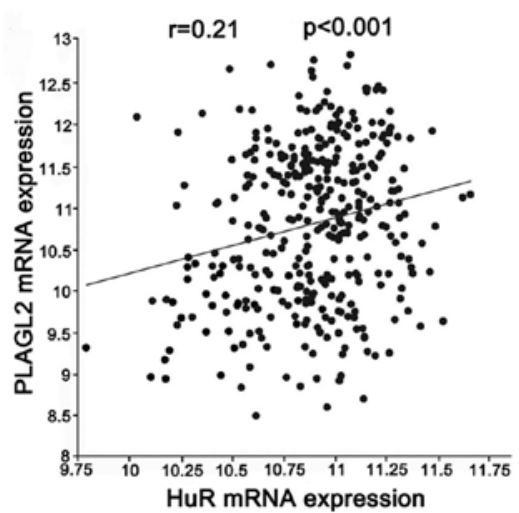

C

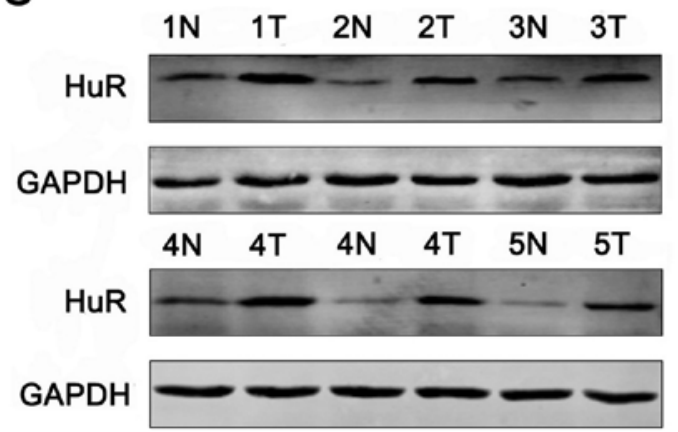

B

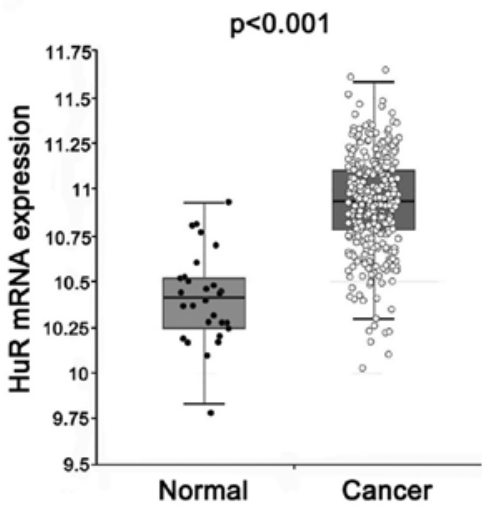

D

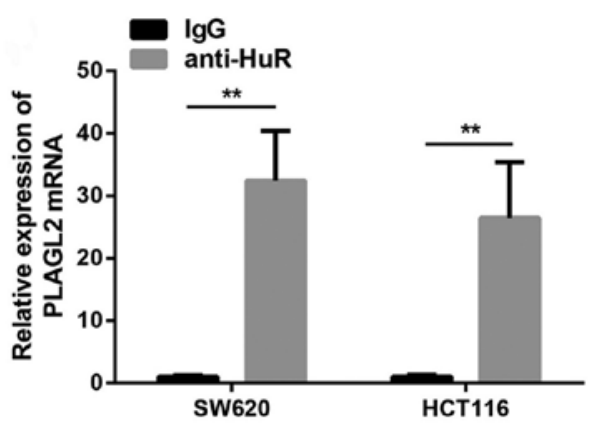

$\mathrm{E}$

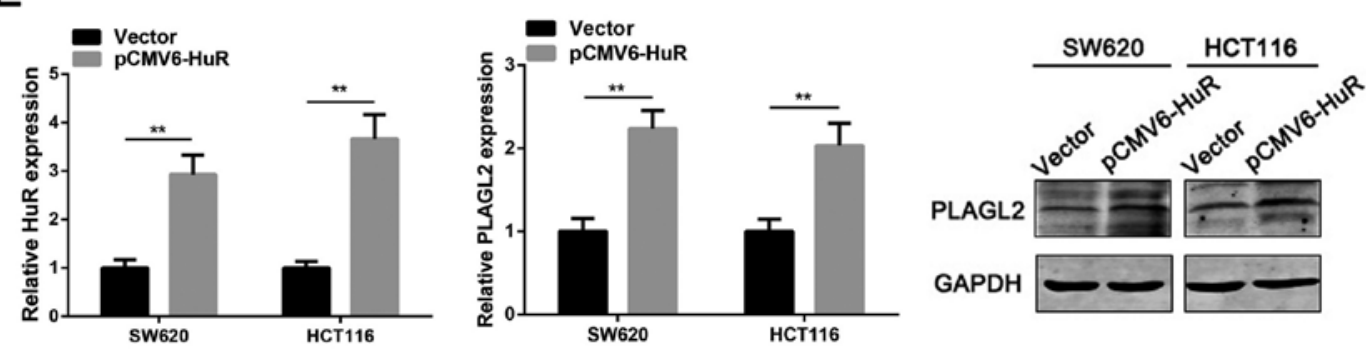

Figure 4. HuR protein may stabilize PLAGL2 mRNA. (A) Correlation analysis between PLAGL2 expression and HuR expression in CRC was analysed using starBase v2.0. (B) HuR expression in CRC samples and normal samples was analysed using starBase v2.0. (C) HuR protein expression in 6 randomly selected, paired CRC tissues and normal tissues, was detected by western blotting. (D) Co-precipitated RNAs put down by HuR protein and IgG (negative control) were detected by RT-qPCR. (E) Following transfection with empty vector (negative control) and pCMV6-HuR (HuR-expressing plasmid), the mRNA expression of HuR and PLAGL2 was detected by RT-qPCR and the protein expression of PLAGL2 were detected by western blotting. Data are presented as the mean \pm standard deviation. ${ }^{* *} \mathrm{p}<0.01$, with comparisons indicated by lines. HuR, human antigen R; PLAGL2, pleomorphic adenoma gene like-2; CRC, colorectal cancer; RT-qPCR, reverse transcription-quantitative polymerase chain reaction.

RIP was used to validate the interaction between HuR and PLAGL2, and HuR antibodies and negative mouse IgG were used for immunoprecipitation of the RIP lysate prepared from SW620 and HCT116 cells. The bound mRNAs were then detected by RT-qPCR. As presented in Fig. 4D, PLAGL2 more specifically interacted with HuR than the control. Furthermore, empty vector and pCMV6-HuR were successfully transfected into SW620 and HCT116 cells and detected the transfection efficiency by RT-qPCR. The expression of PLAGL2 in the cells transfected with pCMV6-HuR was significantly increased at the mRNA and protein levels compared with the control (Fig. 4E). Therefore, these results indicated that overexpressed HuR may stabilize the expression of PLAGL2.

PLAGL2 3'-UTR promotes the progression of CRC in vitro. Next, 20 pairs of CRC tissues were tested, and PLAGL2 3'-UTR was also revealed to be overexpressed in CRC tissues compared with normal tissues. Furthermore, the full length of 3'-UTR expression was significantly increased compared with PLAGL2 mRNA expression in normal tissues and cancer tissues, and these expression ratios were not statistically significant between normal and cancer (Fig. 5A). A previous study has demonstrated that 3'-UTRs are expressed separately from their associated protein-coding sequences and regulate cellular function (14). To explore the function of PLAGL2 3'-UTR in CRC progression, two lentivirus termed PLAGL2 3'-UTR Front and PLAGL2 3'-UTR Back ('LV-PLAGL2 3'-UTR Front' being a lentivirus constructed with the front 2,000 bp of PLAGL2 3'UTR, 'LV-PLAGL2 3'-UTR Back' being a lentivirus constructed with the back 1,948bp of PLAGL2 3'-UTR) to stably overexpress PLAGL2 3'-UTR in SW620 and HCT116 cells, and expression was detected by RT-qPCR (Fig. 5B). Transwell migration assays revealed that overexpressed PLAGL2 3'-UTR promoted cell migration compared with the control, and similar results were obtained from the Transwell invasion assay (Fig. 5C). A CCK-8 assay was performed to evaluate the 
A

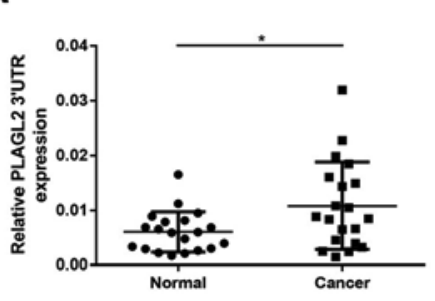

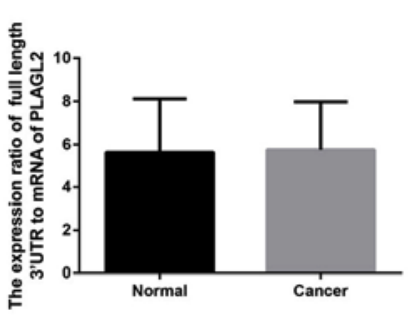

B

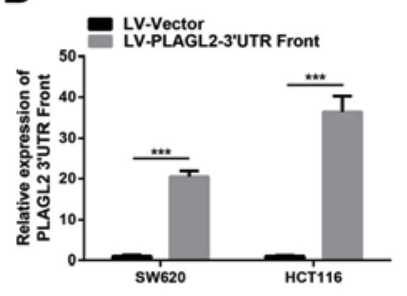

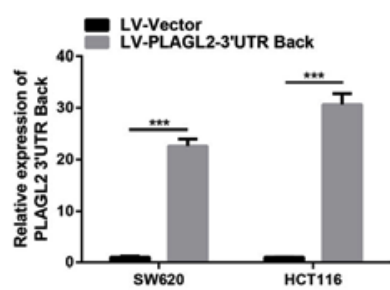

C
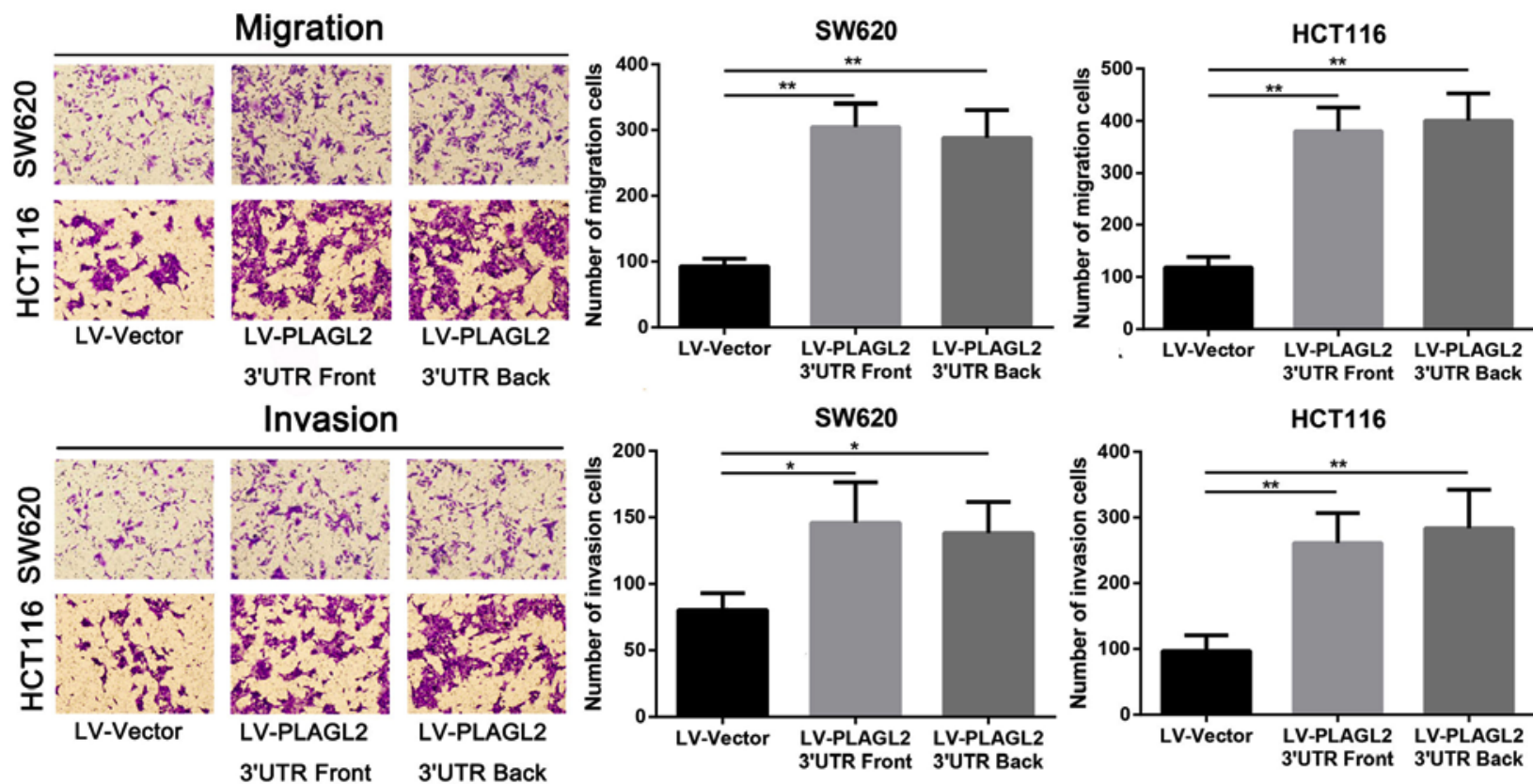

D
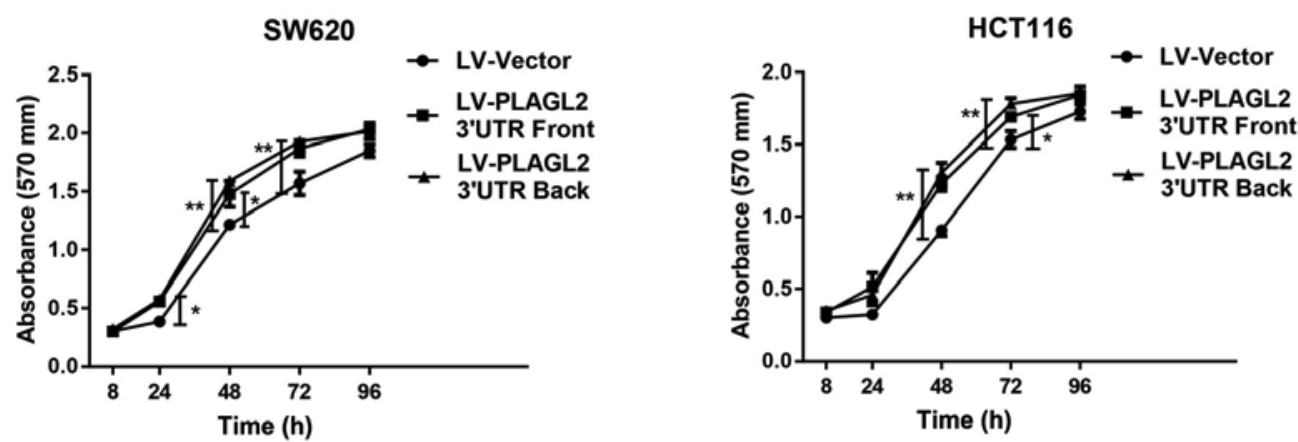

Figure 5. The effects of PLAGL2 3'-UTR on the progression of CRC in vitro. (A) PLAGL2 3'UTR expression and the expression ratio of full length 3'-UTR to mRNA in CRC tissues and normal tissues $(\mathrm{n}=20)$ was detected by RT-qPCR. (B) The mRNA of PLAGL2 3'-UTR Front and PLAGL2 3'-UTR Back were detected by RT-qPCR in SW620 and HCT116 cells following transfection with lentivirus ('LV-Vector' means negative control, 'LV-PLAGL2 3'-UTR Front' means lentivirus constructed with the front 2,000 bp of PLAGL2 3'-UTR and 'LV-PLAGL2 3'-UTR Back' means lentivirus constructed with the back 1,948 bp of PLAGL2 3'-UTR). (C) Migration, invasion and (D) proliferation in SW620 and HCT116 cells was detected by Transwell assays and cell counting Kit-8 assays following transfection with lentivirus. Data are presented as the mean \pm standard deviation. ${ }^{*} \mathrm{p}<0.05,{ }^{* *} \mathrm{p}<0.01$ and ${ }^{* * *} \mathrm{p}<0.001$, with comparisons indicated by lines. PLAGL2, pleomorphic adenoma gene like-2; 3'-UTR, 3'-untranslated region; CRC, colorectal cancer; RT-qPCR, reverse transcriptionquantitative polymerase chain reaction.

overexpression of PLAGL2 3'-UTR on cell viability, and results revealed that the proliferation of CRC cells was significantly increased in a time-dependent manner (Fig. 5D). These results verified the non-coding function of PLAGL2 3'-UTR for the first time in in vitro experiments.

PLAGL2 3'-UTR promotes tumor growth in vivo. To investigate the in vivo carcinogenicity of PLAGL2 3'-UTR, SW620 and HCT116 cells that were transfected with lentivirus were subcutaneously injected into nude mice. Consistent with the in vitro results, the experimental groups (LV-PLAGL2 3'-UTR Front and LV-PLAGL2 3'-UTR Back) showed significant promotion of tumor growth compared with the control groups (LV-Vector) (Fig. 6A and B). The tumor weight of the experimental groups was also significantly increased compared with the control groups (Fig. 6C). These results verified the non-coding function of PLAGL2 3'-UTR for the first time in in vivo experiments. 
A

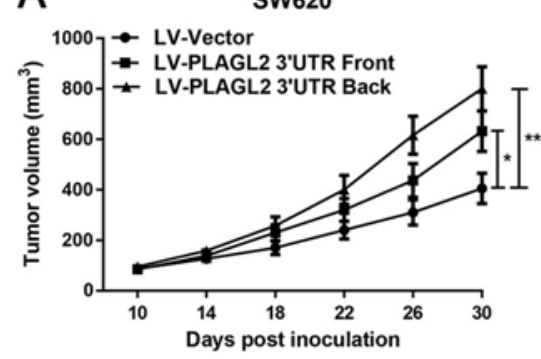

HCT116

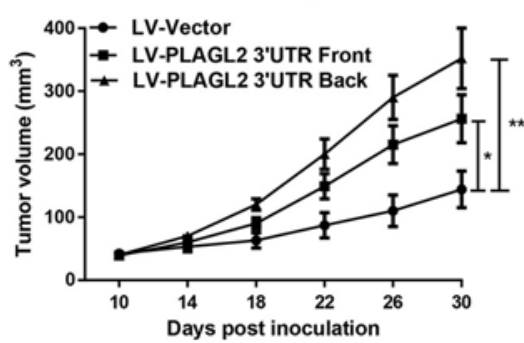

B

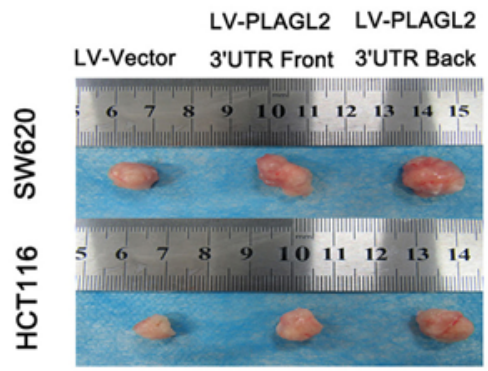

C

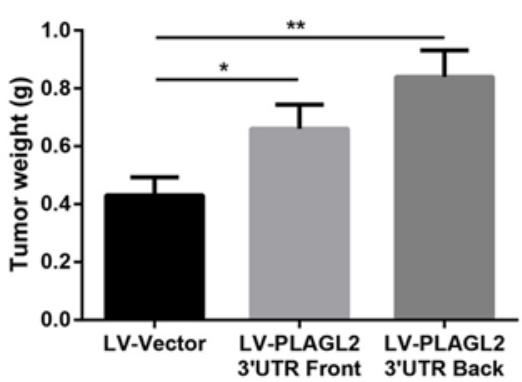

HCT116

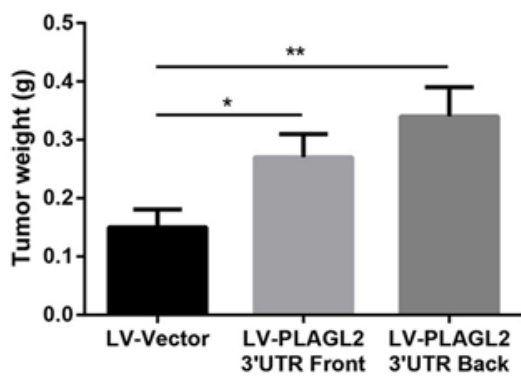

Figure 6. The effects of PLAGL2 3'-UTR on tumor growth in vivo. (A) Growth curve. The tumor volume was measured every 3 days from 10 days after inoculation. (B) Representative images of tumors, with (C) quantification. Tumors were removed and weighed on the 30 th day following inoculation ( $\mathrm{n}=5$ for each group). Data are presented as the mean \pm standard deviation. ${ }^{*} \mathrm{p}<0.05$ and ${ }^{* *} \mathrm{p}<0.01$, with comparisons indicated by lines. PLAGL2, pleomorphic adenoma gene like-2; 3'-UTR, 3'-untranslated region.

PLAGL2 3'-UTR regulates the expression of $C-M Y C$ and CD44 in CRC cells. Several studies have reported that mRNA 3'-UTR regulates the expression of ceRNAs and thus participates in the progression of tumors $(15,16)$. Therefore, our group investigated whether PLAGL2 3'-UTR also functions in a regulatory manner, and preliminarily screened out potential ceRNA genes of PLAGL2 3'-UTR. A total of 14 candidate genes were selected through literature review, informatics analysis and starBase v2.0 prediction. As presented in Fig. 7A, there are multiple common miRNAs between all candidate genes and PLAGL2. Then, PLAGL2 3'-UTR was overexpressed in SW620 and HCT116 cells using LV-PLAGL2 3'-UTR Front and LV-PLAGL2 3'-UTR Back, and the mRNA levels of C-MYC and CD44 were significantly increased compared with the control groups (Fig. 7B and C). Western blotting further confirmed that C-MYC and CD44 protein expression was increased in CRC cells in the overexpression groups compared with the control groups (Fig. 7D). These results at least indicated that PLAGL2 3'-UTR regulated the expression of C-MYC and CD44 in CRC cells.

\section{Discussion}

Copy number variation (CNV) is defined as a DNA segment $(>1 \mathrm{~kb})$ that shows copy number differences among the normal population, and is a genetic variation widely found in the human genome (25). Several studies have reported that gene CNV is a significant influential factor for gene expression $(13,26,27)$. For instance, phosphatidylinositol-4,5-bisphosphate 3-kinase catalytic subunit $\alpha$ (PIK3CA) amplification drives the expression of PIK3CA in gastric cancer (26), CNV are significantly associated with MYC mRNA and protein expression (27), and the deregulation of cancer genes including APC, fibroblast growth factor receptor 2 , and erb-b2 receptor tyrosine kinase 2 depend on CNV in CRC (28). Furthermore, the results of the present study revealed that PLAGL2 expression was positively correlated with $\mathrm{CNV}$, which indicated the function of $\mathrm{CNV}$ in the mechanism of PLALG2 overexpression in CRC. CNV has been confirmed to have diagnostic, prognostic or therapeutic significances in various types of cancer $(12,26,29)$. Notably, PLAGL2 is located in 20q11, and CNV of chromosome 20q11 is an important event in the process of colon cancer. In the present study, our group identified an association between CNV and the expression of PLAGL2 in CRC, and several studies have demonstrated that PLAGL2 serves an oncogenic function in CRC $(9,10)$. Therefore, it is necessary to further study the potential value of PLAGL2 CNV in the diagnosis, treatment and prognosis of CRC in a follow-up study.

As a cis-regulatory element, 3'-UTRs regulate mRNA expression, stability and subcellular localization by interacting with trans-acting factors (30), miRNAs and RBPs are two important trans-acting factors and research hot spots in the regulation of gene expression (30). Therefore, it is necessary to examine post-transcriptional regulation mediated by 3 '-UTRs to explore the regulatory mechanisms of gene expression.

miR-486-5p has been demonstrated to regulate the expression of target genes by binding to the 3'-UTR, and to function as a tumor suppressor in multiple malignant tumors, including prostate cancer, lung cancer, hepatocellular carcinoma and CRC (20,31-33). Consistent with these studies, our group also analyzed potential PLAGL2-associated miRNAs using bioinformatics analysis and demonstrated that the expression of PLAGL2 is regulated by miR-486-5p in CRC cells. However, whether miR-486-5p is involved in CRC progression via the regulation of PLAGL2 remains unclear, and a further study is required to explain the anti-cancer mechanisms of miR-486-5p 


\begin{tabular}{|c|c|c|c|c|c|c|c|c|c|c|c|c|c|c|}
\hline & \multicolumn{10}{|c|}{ Possible candidate ceRNAs } \\
\hline Gene name & VIM & SRC & RHOC & $\begin{array}{c}\text { RPS6K } \\
\text { A3 }\end{array}$ & PRL-3 & C-MYC & KMT2D & MAVS & LARP1 & HMGA2 & EZH2 & E2F3 & CD44 & $\begin{array}{c}\text { C22OR } \\
\text { F29 }\end{array}$ \\
\hline $\begin{array}{c}\text { Common miRNAs } \\
\text { with PLAGL2 }\end{array}$ & 9 & 67 & 37 & 108 & 41 & 50 & 70 & 165 & 93 & 78 & 9 & 78 & 76 & 120 \\
\hline
\end{tabular}
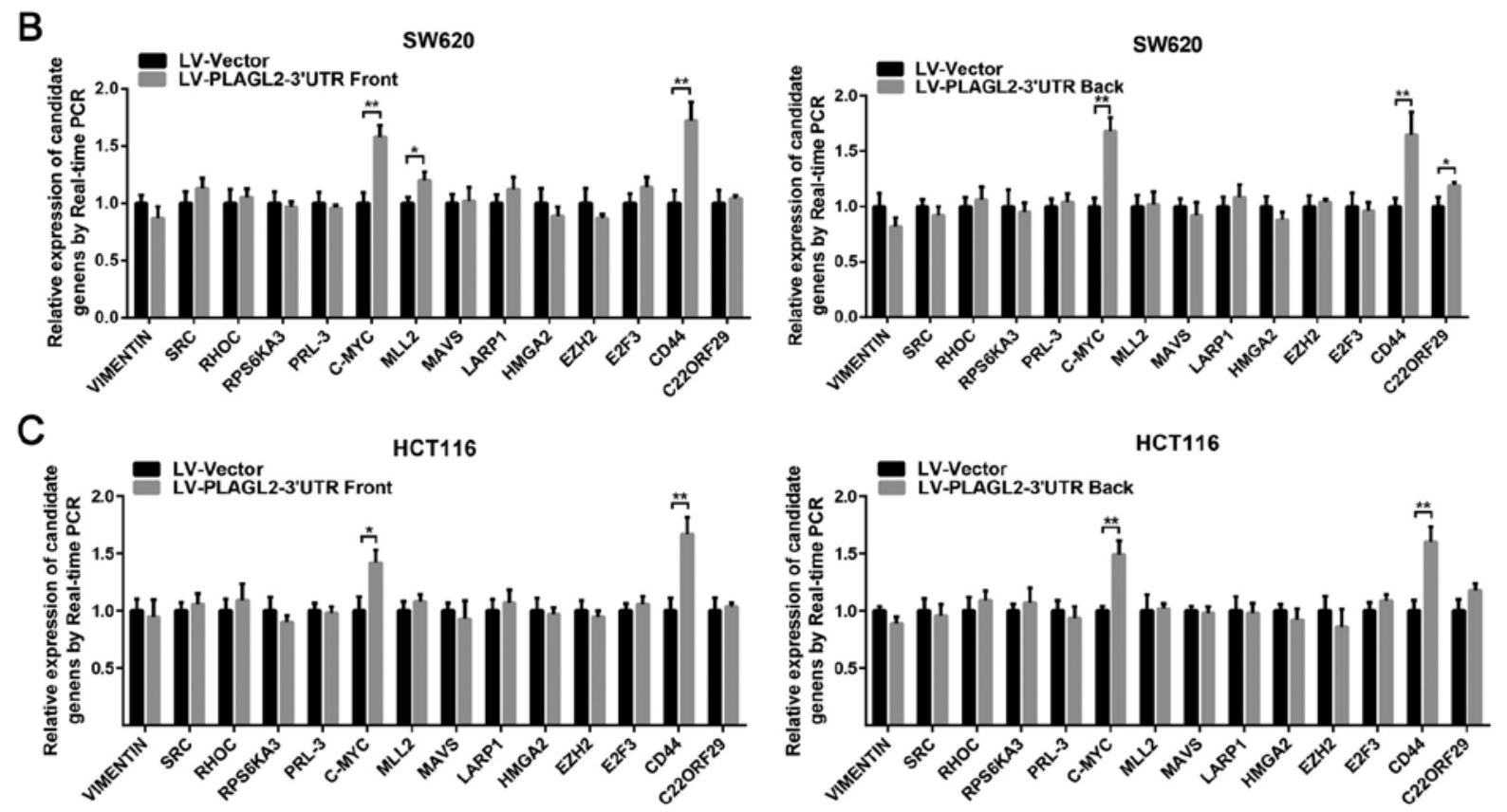

D

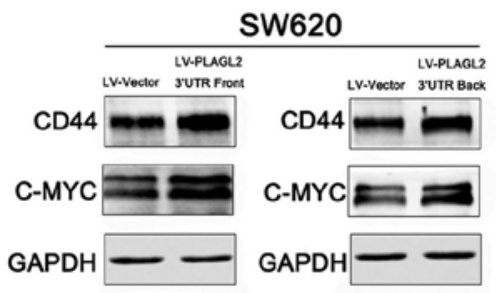

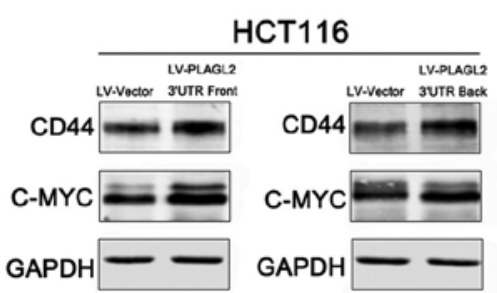

Figure 7. C-MYC and CD44 expression were regulated by PLAGL2 3'-UTR. (A) A chart shows the potential candidate ceRNA genes of PLAGL2 3'-UTR. The mRNA expression of candidate ceRNAs in (B) SW620 and (C) HCT116 cells were detected by reverse transcription-quantitative polymerase chain reaction following transfection with lentivirus. (D) Protein expression of C-MYC and CD44 in SW620 and HCT116 cells were detected by western blotting following transfection with lentivirus. Data are presented as the mean \pm standard deviation. * $\mathrm{p}<0.05$ and ${ }^{* *}$ p $<0.01$, with comparisons indicated by lines. PLAGL2, pleomorphic adenoma gene like-2; 3'-UTR, 3'-untranslated region; ceRNA, competing endogenous RNA.

in CRC. However, the present study identified a target miRNA of PLAGL2, which provided a novel mechanism through which to study the overexpression of PLAGL2.

As a well-known RNA binding protein, HuR serves an important function in the regulation of mRNA stability by binding to AU-rich element of mRNA 3'-UTR $(21,22)$. Long non-coding RNA (lncRNA) NEAT1, cyclin dependent kinase 3 , vascular endothelial growth factor, mitogen-activated protein kinase phosphatase 1 and tumor necrosis factor- $\alpha$ are all stabilized by HuR (23,34-35). The results of the present study also indicated that HuR may stabilize the expression of PLAGL2 in CRC, which demonstrated another mechanism of PLAGL2 overexpression at the level of RBP. HuR has been increasingly recognized as a novel factor in terms of diagnosis, prognosis, and therapy in various types of cancer, via the stabilization of cancer-associated gene expression (23). In the present study, HuR was revealed to be overexpressed in $\mathrm{CRC}$, which was consistent with the oncogenic function of PLAGL2 in CRC. Abdelmohsen and Gorospe (23) and Kotta-Loizou et al (24) also mentioned the clinical significance of HuR overexpression in CRC $(23,24)$. Thus, these results also provided a novel target mRNA through which HuR may be involved in the progression of CRC.

The independent expression of 3'-UTRs, separate from their matched protein-coding regions, is a widespread phenomenon (14). To a certain extent, the 3'-UTR represents a specific archetype of lncRNA, which may exert biological functions different from their associated mRNAs $(14,36)$. With the appearance of the ceRNA hypothesis, an increasing number of studies have indicated that the 3'-UTR of mRNAs may exert a noncoding function, which is involved in the progression of tumors and regulates the expression of ceRNAs $(15,16,37)$. For instance, overexpression of the CD44 3'-UTR increases cell 
motility and invasion in the human breast carcinoma cell line MDA-MB-231 through sponging multiple miRNAs, and thus modulated Coll $\alpha 1$ and FN1 (15). Versican 3'-UTR functions as a ceRNA and regulates the expression of CD34 and fibronectin by regulating miRNA activity and inducing the development of hepatocellular carcinoma (16). X-linked inhibitor of apoptosis 3'-UTR, as a ceRNA, promotes FSCN1 function in the induction of breast cancer progression by binding endogenous miRNA (37). Similar to the above findings, the results of the present study demonstrated that PLAGL2 3'-UTR promoted the progression of $\mathrm{CRC}$ and regulated the expression of potential ceRNA genes including C-MYC and CD44. The carcinogenic functions of C-MYC and CD44 have been frequently demonstrated in CRC $(38,39)$. However, whether PLAGL2 3'-UTR regulated the development of CRC through the ceRNA network was unclear. Regardless, in the present study, our group demonstrated that overexpressed PLAGL2 3'-UTR upregulated the expression of C-MYC and CD44, and a further study is required to investigate the exact molecular mechanism of this network.

In summary, the present study initially explored three mechanisms to explain PLAGL2 overexpression, including gene CNV, regulation of miR-485-5p and stabilization of HuR protein. Then, overexpression of PLAGL2 3'-UTR was demonstrated to promote progression of $\mathrm{CRC}$ in in vitro and in vivo experiments, and a preliminary screening result indicated that C-MYC and CD44 were regulated by PLAGL2 3'-UTR in CRC cells. These results provided important information regarding our understanding of the impact of PLAGL2 on CRC pathogenesis, and suggested that PLAGL2 3'-UTR may be a novel biomarker for targeted therapies in CRC.

\section{Acknowledgements}

Not applicable.

\section{Funding}

The present study was supported by grants from the New Xiangya Talent Projects of the Third Xiangya Hospital of Central South University (nos. 20150306 and JY201611). This study was also supported by grants from the National Natural Science Foundation of China (nos. 81602568 and 81773130).

\section{Availability of data and materials}

The bioinformatics data analysis used in our study can be obtained from the following website: TCGA database (http://www. cbioportal.org/), COSMIC database (http://cancer.sanger.ac.uk/ cosmic/), TargetScan (http://www.targetscan.org), Starbase v2.0 (http://starbase.sysu.edu.cn/index.php), Tarbase (http://carolina. imis.athena-innovation.gr) and miRTarBase (http://mirtarbase. mbc.nctu.edu.tw/php/index.php). The authors also declared that the materials described in this manuscript, will be freely available to any scientist wishing to use them for non-commercial purposes.

\section{Authors' contributions}

Article checking and project design were carried out by $\mathrm{YZ}$ and XL; the experimental design, writing, and cell experiments were performed by CS and DL; the tissue experiments were performed by NL; the animal experiments were performed by YD; figure editing and statistical analysis were performed by $\mathrm{CY}$ and YB; and specimen collection was carried out by CL.

\section{Ethics approval and consent to participate}

Signed consent forms were provided by each patient, and the present study was approved by The Institute Research Medical Ethics Committee of Central South University (Changsha, China) (no. 2018-S012). The animal protocols were approved by the Animal Ethics Committee of Central South University.

\section{Consent for publication}

Not applicable.

\section{Competing interests}

The authors declare that they have no competing interests.

\section{References}

1. Wezensky SJ, Hanks TS, Wilkison MJ, Ammons MC, Siemsen DW and Gauss KA: Modulation of PLAGL2 transactivation by positive cofactor 2 (PC2), a component of the ARC/Mediator complex. Gene 452: 22-34, 2010.

2. Kas K, Voz ML, Hensen K, Meyen E and Van de Ven WJ: Transcriptional activation capacity of the novel PLAG family of zinc finger proteins. J Biol Chem 273: 23026-23032, 1998.

3. Furukawa T, Adachi Y, Fujisawa J, Kambe T, Yamaguchi-Iwai Y, Sasaki R, Kuwahara J, Ikehara S, Tokunaga R and Taketani S: Involvement of PLAGL2 in activation of iron deficientand hypoxia-induced gene expression in mouse cell lines. Oncogene 20: 4718-4727, 2001.

4. Van Dyck F, Declercq J, Braem CV and Van de Ven WJ: PLAG1, the prototype of the PLAG gene family: Versatility in tumour development (Review). Int J Oncol 30: 765-774, 2007.

5. Hanks TS and Gauss KA: Pleomorphic adenoma gene-like 2 regulates expression of the p53 family member, p73, and induces cell cycle block and apoptosis in human promonocytic U937 cells. Apoptosis 17: 236-247, 2012.

6. Zheng H, Ying H, Wiedemeyer R, Yan H, Quayle SN, Ivanova EV, Paik JH, Zhang H, Xiao Y, Perry SR, et al: PLAGL2 regulates Wnt signaling to impede differentiation in neural stem cells and gliomas. Cancer Cell 17: 497-509, 2010.

7. Landrette SF, Kuo YH, Hensen K, Barjesteh van Waalwijk van Doorn-Khosrovani S, Perrat PN, Van de Ven WJ, Delwel R and Castilla LH: Plag1 and Plag12 are oncogenes that induce acute myeloid leukemia in cooperation with Cbfb-MYH11. Blood 105: 2900-2907, 2005.

8. Yang YS, Yang MC and Weissler JC: Pleiomorphic adenoma gene-like 2 expression is associated with the development of lung adenocarcinoma and emphysema. Lung Cancer 74: 12-24, 2011.

9. Liu B, Lu C, Song YX, Gao P, Sun JX, Chen XW, Wang MX, Dong YL, Xu HM and Wang ZN: The role of pleomorphic adenoma gene-like 2 in gastrointestinal cancer development, progression, and prognosis. Int J Clin Exp Pathol 7: 3089-3100, 2014.

10. Wang YP, Guo PT, Zhu Z, Zhang H, Xu Y, Chen YZ, Liu F and Ma SP: Pleomorphic adenoma gene like-2 induces epithelialmesenchymal transition via Wnt/ $\beta$-catenin signaling pathway in human colorectal adenocarcinoma. Oncol Rep 37: 1961-1970, 2017.

11. Li DJ, Lin CW, Chen M, Li NP, Du YH, Su C, Yang CX, Gong N, Wu H, Wu RL, et al: Comprehensive bioinformatics analysis of the characterization and determination underlying mechanisms of over-expression and co-expression of genes residing on $20 \mathrm{q}$ in colorectal cancer. Oncotarget 8: 78642-78659, 2017.

12. Liang L, Fang JY and Xu J: Gastric cancer and gene copy number variation: Emerging cancer drivers for targeted therapy. Oncogene 35: 1475-1482, 2016.

13. Yang Z, Zhuan B, Yan Y, Jiang S and Wang T: Integrated analyses of copy number variations and gene differential expression in lung squamous-cell carcinoma. Biol Res 48: 47, 2015. 
14. Mercer TR, Wilhelm D, Dinger ME, Soldà G, Korbie DJ, Glazov EA, Truong V, Schwenke M, Simons C, Matthaei KI, et al: Expression of distinct RNAs from 3' untranslated regions. Nucleic Acids Res 39: 2393-2403, 2011.

15. Rutnam ZJ and Yang BB: The non-coding 3' UTR of CD44 induces metastasis by regulating extracellular matrix functions. J Cell Sci 125: 2075-2085, 2012.

16. Fang L, Du WW, Yang X, Chen K, Ghanekar A, Levy G, Yang W, Yee AJ, Lu WY, Xuan JW, et al: Versican 3'-untranslated region (3'-UTR) functions as a ceRNA in inducing the development of hepatocellular carcinoma by regulating miRNA activity. FASEB J 27: 907-919, 2013.

17. Lewis BP, Burge CB and Bartel DP: Conserved seed pairing, often flanked by adenosines, indicates that thousands of human genes are microRNA targets. Cell 120: 15-20, 2005.

18. Bartel DP: MicroRNAs: Target recognition and regulatory functions. Cell 136: 215-233, 2009.

19. Chen K and Rajewsky N: The evolution of gene regulation by transcription factors and microRNAs. Nat Rev Genet 8: 93-103, 2007.

20. Liu C, Li M, Hu Y, Shi N, Yu H, Liu H and Lian H: miR-486-5p attenuates tumor growth and lymphangiogenesis by targeting neuropilin-2 in colorectal carcinoma. Onco Targets Ther 9: 2865-2871, 2016

21. Lebedeva S, Jens M, Theil K, Schwanhäusser B, Selbach M, Landthaler M and Rajewsky N: Transcriptome-wide analysis of regulatory interactions of the RNA-binding protein HuR. Mol Cell 43: 340-352, 2011.

22. Brennan CM and Steitz JA: HuR and mRNA stability. Cell Mol Life Sci 58: 266-277, 2001.

23. Abdelmohsen $\mathrm{K}$ and Gorospe M: Posttranscriptional regulation of cancer traits by HuR. Wiley Interdiscip Rev RNA 1: 214-229, 2010

24. Kotta-Loizou I, Giaginis C and Theocharis S: Clinical significance of HuR expression in human malignancy. Med Oncol 31 161,2014

25. Scherer SW, Lee C, Birney E, Altshuler DM, Eichler EE, Carter NP, Hurles ME and Feuk L: Challenges and standards in integrating surveys of structural variation. Nat Genet 39 (Suppl 7): S7-S15, 2007

26. Shi J, Yao D, Liu W, Wang N, Lv H, Zhang G, Ji M, Xu L, He N Shi B, et al: Highly frequent PIK3CA amplification is associated with poor prognosis in gastric cancer. BMC Cancer 12: 50, 2012.

27. de Souza CR, Leal MF, Calcagno DQ, Costa Sozinho EK, Borges BN, Montenegro RC, Dos Santos AK, Dos Santos SE, Ribeiro HF, Assumpção PP, et al: MYC deregulation in gastric cancer and its clinicopathological implications. PLoS One 8: e64420, 2013.

28. Camps J, Nguyen QT, Padilla-Nash HM, Knutsen T, McNeil NE, Wangsa D, Hummon AB, Grade M, Ried T and Difilippantonio MJ Integrative genomics reveals mechanisms of copy number alterations responsible for transcriptional deregulation in colorectal cancer. Genes Chromosomes Cancer 48: 1002-1017, 2009.
29. Tanenbaum DG, Hall WA, Colbert LE, Bastien AJ, Brat DJ, Kong J, Kim S, Dwivedi B, Kowalski J, Landry JC, et al: TNFRSF10C copy number variation is associated with metastatic colorectal cancer. J Gastrointest Oncol 7: 306-314, 2016.

30. Kuersten S and Goodwin EB: The power of the 3' UTR: Translational control and development. Nat Rev Genet 4: 626-637, 2003.

31. Zhang X, Zhang T, Yang K, Zhang M and Wang K: miR-486-5p suppresses prostate cancer metastasis by targeting Snail and regulating epithelial-mesenchymal transition. Onco Targets Ther 9: 6909-6914, 2016.

32. Wang J, Tian X, Han R, Zhang X, Wang X, Shen H, Xue L, Liu Y, Yan X, Shen J, et al: Downregulation of miR-486-5p contributes to tumor progression and metastasis by targeting protumorigenic ARHGAP5 in lung cancer. Oncogene 33: 1181-1189, 2014

33. Youness RA, El-Tayebi HM, Assal RA, Hosny K, Esmat G and Abdelaziz AI: MicroRNA-486-5p enhances hepatocellular carcinoma tumor suppression through repression of IGF-1R and its downstream mTOR, STAT3 and c-Myc. Oncol Lett 12: 2567-2573, 2016.

34. Chai Y, Liu J, Zhang Z and Liu L: HuR-regulated lncRNA NEAT1 stability in tumorigenesis and progression of ovarian cancer. Cancer Med 5: 1588-1598, 2016.

35. Zhang Z, Huang A, Zhang A and Zhou C: HuR promotes breast cancer cell proliferation and survival via binding to CDK3 mRNA. Biomed Pharmacother 91: 788-795, 2017.

36. $\mathrm{Li} \mathrm{J}$ and $\mathrm{Lu} \mathrm{X}$ : The emerging roles of 3 untranslated regions in cancer. Cancer Lett 337: 22-25, 2013.

37. Wu Q, Yan H, Tao SQ, Wang XN, Mou L, Chen P, Cheng XW, Wu WY and Wu ZS: XIAP 3'-untranslated region as a ceRNA promotes FSCN1 function in inducing the progression of breast cancer by binding endogenous miR-29a-5p. Oncotarget 8: 16784-16800, 2017.

38. Garte SJ: The c-myc oncogene in tumor progression. Crit Rev Oncog 4: 435-449, 1993.

39. Du L, Wang H, He L, Zhang J, Ni B, Wang X, Jin H, Cahuzac N, Mehrpour M, Lu Y, et al: CD44 is of functional importance for colorectal cancer stem cells. Clinical cancer research: an official journal of the American Association for Cancer Research 14: 6751-6760, 2008.

This work is licensed under a Creative Commons Attribution-NonCommercial-NoDerivatives 4.0 International (CC BY-NC-ND 4.0) License. 